\author{
Associate Professor Oana-Ramona LOBONT, PhD \\ West University of Timisoara \\ Professor Nicoleta-Claudia MOLDOVAN,PhD \\ West University of Timisoara \\ Alexandru BOCIU, PhD Student (Corresponding author) \\ West University of Timisoara \\ Associate Professor Codruta CHIS,PhD \\ Banat University of Agricultural Sciences and Veterinary Medicine \\ Lectures Daniel BRÎNDESCU OLARIU, PhD \\ West University of Timisoara
}

\title{
A FACTOR ANALYSIS OF THE PUBLIC SECTOR PERFORMANCE. SIGNIFICANT DIFFERENCES BETWEEN OLD AND NEW EU COUNTRIES
}

\begin{abstract}
This paper revisits public sector performance analysis for EU states during 1995-2014 using principal component analysis technique. The following approaches are considered: (i) analysis of public sector performance and (ii) identification of the most important subsector. In order to compare the EU countries public sector performance, we considered seven subsectors, namely, administration, health, education, infrastructure, income distribution, economic stability and economic performance. Results emphasize that administration subsector has a major contribution in achieving public sector performance. The results indicate that EU old countries have the best competitive potential for prospectively furthering sustainable development. Only four EU states register a discordant behavior. Greece and Italy represent old EU states that aren't performant and Malta and Cyprus represent the new EU states that are performant. These findings are relevant to national policy sustainable development agendas, at different levels, considering development as one of the most important issue for policy-makers and public managers.
\end{abstract}

Keywords: public sector performance, composite index, EU countries, Principal Component Analysis, development.

\section{JEL Classification: C38, H11, O52}

\section{Introduction}

This paper reexamines public sector performance for the EU Member States. In this process, the most important subsectors of the public environment are considered, namely, administration, health, education, infrastructure, income distribution, economic stability and economic performance. In 2015, the EU Council 
adopted a new set of integrated guidelines in the Europe 2020 strategy. The strategy offers directions for the economic policies of the Member States to ensure sustainable economic growth by 2020. A careful analysis of the development process in European countries highlights that the economic dimension no longer needs to be marginalized in mainstream approaches. Promoting growth and development, political stability, social or environmental sustainable strategies are of particular importance. Therefore, the macrostructural policy framework should be a more consistent contribution from European policies to the objectives of the Europe 2020 strategy. Sound public policies are a key for growth; national strategies should prioritize growth-enhancing expenditures within social areas such as education and health, infrastructure, income distribution, economic stability or innovation. It is also essential not to ignore the importance of a performant and sustainable public sector, especially on the public administration level, due to its effect on the competitiveness of Member States. The EU's growth strategy emphasizes the importance of effective and transparent public administration, whose modernization is a key issue in restoring competitiveness in a number of Member States. Both structure and scope of the public sector, though public institutions and public policies are specific for each country, and their architecture are occurring in competency management at the national level of government. Thus, it is important to determine the opportunities and challenges for a government as a promoter for development.

This paper contributes to the literature by a quantitative analysis of the European Union Member Countries' performance. In this sense, a ranking of the EU states is made to homogeneous units (clusters) according to performance results and their status as old and new EU countries. The achievements in different public sectors areas for EU old and new countries will be a reference to identify the best competitive potential and perspective to further sustainable development.

In this paper, the overall assumption behind the assessment of public sector performance is that, the observed and expected outcome indicators, explain the results of public spending policies' impact. Performance evaluation should be integral parts of a national agenda for reform.

Hereinafter this paper is organized as follows: Section 2 considers a brief review of the related literature in terms of public sector performance. We also provide the methodology that aims to explain the performance of public institutions and public policies in the light of their key characteristics and the described dataset. Finally, section 3 reports the robustness of our empirical results and section 4 concludes with recommendations.

\section{Literature review}

The enquiry of public sector performance is useful for the national policy agenda. It offers recommendations for improving the performance of various public 
A Factor Analysis of the Public Sector Performance. Significant Differences between Old and New EU Countries

fields by adopting the best practices of other countries or by responding to different socioeconomic, political or environmental challenges.

Many authors and international organizations compute both public sector performance (PSP) and public sector efficiency indicators (PSE) for various public sectors as a whole and for its core functions. The assessment of public sector efficiency and public sector performance requires different input and output data. Most studies use input and output data to measure efficiency by reference to the production possibility frontier. The suitable research methodology seems to be related to parametric and non-parametric frameworks.

Nevertheless, the consensus regarding the measurement of the public sector performance and efficiency is still very limited. This paper provides a proxy for measuring public sector performance and efficiency by using composite indices built on account of different subsectors of the public sector. Divergent views have been considered to define the relevant subsectors of the public sector. Afonsoet al. (2003, 2006, 2013) define seven significant sub-indicators, namely, "process" or "opportunity" indicators, such as administration, education, health and public infrastructure outcomes, and the "Musgravian" tasks for the government considering income distribution, economic stability and economic performance.

Using the methodology developed by Afonsoet al. (2006) to measure the efficiency of the public sector, Angelopoulos et al. (2008) performed the construction of composite indices referring only to four dimensions specific to the public sector, namely, administration, stability, infrastructure and education. In addition, the mentioned authors estimate technical efficiency by applying stochastic production frontier analysis, incorporating the two measures, both Public Sector Efficiency and Technical Efficiency into an econometric model.

Therefore, we note that studies in this field highlight two types of performance indicators of the public sector, specifically $(i)$ process or opportunity indicators; and (ii) traditional or Musgravian indicators. Thus, based on the study by Afonso et al. (2006) and Rouag and Stejskal (2014), we can distinguish between these indicators using cluster analysis methodology to develop two composite sub-indicators that measure performance.

It is important to mention that identifying several indicators that measure the efficiency and performance of the public sector has been a concern not only for the academic environment but also for many international bodies. Thus, a robust framework for comparison between states regarding the public sector is relevant in terms of institutional, decision-making perspective and the quality of public policies. In this regard, we consider the perspective offered by Kaufmann et al. (1999a), which considers the three dimensions of bureaucratic quality, the rule of law and graft necessary for the assessment of governance, to be significant. Currently, the set of governance measuring indicators named The Worldwide Governance Indicators, developed by Kaufmann et al. (2010) is available for approximately 200 countries and highlights the following six governance 
dimensions:" i) voice and accountability, ii) political stability and absence of violence or terrorism, iii) government effectiveness, $i v$ ) regulatory quality, $v$ ) rule of law and vi) control of corruption". The OECD (2007) supports the development of a robust comparison framework by classifying data on the following four levels: outcomes (sub-central public revenue), inputs (general mix of inputs and work), processes (budgetary procedures and practices, human resource management, integrated E-government systems, governance centers, quality management) and outputs (central government). Transparency International, through the studies of Lambsdorff (2005), who created the Corruption Perceptions Index (CPI), considers the public sector to be highlighted not only by corruption, but also by the quality of governance.

The World Bank proposes to measure the quality of public policies in line with economic growth and poverty reduction through the Country Policy and Institutional Assessment index (CPIA). This index is obtained by aggregating, in equal weight, twenty criteria clustered in four basic areas, namely, $i$ ) economic management, ii) structural policies, iii) equity and $i v$ ) public sector management and institutions.

The World Economic Forum uses the Growth Competitiveness Index (GCI), which consists of three basic dimensions both in the process of economic growth as well as for the measurement of a country's general performance, i.e., i) the quality of the macroeconomic environment, ii) the state of a country's public institutions and, given the increasing importance of technology in the development process, iii) a country's technological readiness. Additionally, to highlight a country's overall performance from a sustainable economic growth perspective, the Institute for Management Development (IMD) has developed the World Competitiveness Yearbook (WCY) indicator. This is achieved by aggregating twenty sub-indicators through four important areas, namely, $i$ ) economic performance, ii) government efficiency, $i i)$ business efficiency and $i v$ ) infrastructure.

Summarizing the wide range of possibilities for sizing different dimensions of public sector performance and efficiency through aggregated indicators, we appreciate the importance of distinguishing between indices and parameters. Tampieri (2005) shows that the parameters are an integral part of the index construction, in accordance with the objectives, resources and indices associated with the indices. Indices of performance measurement are obtained by considering some weighted averaged parameters, allocating to each one a weight or relevance in the index construction.

\section{Methodology and data}

There are some very rigorous parametric and non-parametric research methods on data quality in support of methodological approaches related to construction and use of public sector performance indicators in cross-country and over-time 
A Factor Analysis of the Public Sector Performance. Significant Differences between Old and New EU Countries

comparison studies. The parametric are generally applied to data intervals, with a Gaussian normal distribution, and the non-parametric ones apply to nominal, ordinal or interval data. Therefore, we consider non-parametric methods more appropriate for social sciences. Although non-parametric tests are less sensitive than parametric tests, we still retain our attention to a parametric method, such as the stochastic frontier analysis originally developed by Aigner et al. (1977), which estimate the so-called Technical Efficiency or Inefficiency of the public sector.

Nonparametric methods assume the existence of a convex production frontier, particularly through the developed by Farrell (1957) and the Free Disposal Hull proposed by Deprins et al.(1984) in previous studies. These methods have become the predominant approach to assess the relative efficiency of public spending across countries and within sectors. Exceeding the model proposed by Farell (1957), Charnes, Cooper \& Rhodes (1978) develop the Data Envelopment Analysis (DEA) methodology based on a linear programming mathematical technique. DEA is capable of determining the efficiency of a decision-making unit (DMU). DEA identifies efficient and inefficient units on the efficiency production frontier. Most importantly, DEA identifies ways to improve inefficient units by considering efficient units to be a good practice pattern. At least one organizational unit will be located on the efficiency frontier, and the others will be enveloped by it. The main DEA models are $i$ ) input oriented (CCR model with constant returns-to-scale, BCC model with variable returns-to-scale and NIRS model non-increasing returns-to-scale); ii) output oriented (CCR model with constant returns-to-scale, BCC model with variable returns-to-scale and NIRS model non-increasing returns-to-scale); iii) lacking orientation (non-oriented model with constant returns-to-scale, multiplicative model with variable returns-to-scale and additive model with variable returns-to-scale).

Unlike DEA, Free Disposal Hull (FDH) does not require the convexity hypothesis and is recommended as a powerful tool for analyzing the efficiency of the public sector. From a technical and empirical point of view, the FDH involves a small number of assumptions about the production technology of a unit when it determines the technical efficiency.

Principal component analysis (PCA), also called factor analysis,is a non-parametric analysis widely used as an effective method for the construction of composite indicators. Mathematically eloquence of PCA is the orthogonal-linear transposing data in a system of coordinates, so that the greatest variance of projection data becomes the first coordinated and the second largest variance becomes the second main component, etc. Cross-country analysis or sector level analyses are important in highlighting best practices for public policies implementation. Non-parametric analysis has the advantage that estimates the relationship between inputs and outputs with minimal assumptions.

We follow the methodology of Afonso et al., (2006) to measure public sector performance. We assume a typology of welfare states, considering the degree to 
which a country guarantees certain basic rights for citizens and stable conditions for growth and development.

The general approach to design a composite index is to select and prepare the variables to be included, to weight and aggregate these variables and finally, to review the aggregation process robustness (OECD, 2007). The factorial analysis, mainly the principal component analysis proves its valences in the process of constructing aggregated indices because it is a mathematical technique developed to connect a set of observed variables to a smaller number of latent dimensions. It also allows the application of more variables for a concept operationalization. Principal component analysis is a widely used and effective method of constructing composite indicators. Mathematically speaking, PCA is defined as an orthogonal-linear transformation transposing data in a system of coordinates so that the greatest variance of projection data becomes the first coordinated and the second largest variance becomes the second main component. Considering a matrix of data, $\mathrm{X}$, with $\mathrm{n}$ rows and $\mathrm{p}$ columns, PCA transforms a $\mathrm{p}$-dimensional set of weight vectors $\mathbf{w}_{(\mathbf{k})}=\left(\mathbf{w}_{1}, \ldots . \mathbf{w}_{\mathbf{p}}\right)_{(\mathbf{k})}$ into a new set of vectors of main components $\mathbf{t}_{\mathbf{i}}=$ $\left(\mathbf{t}_{1}, \ldots . \mathbf{t}_{\mathrm{m}}\right)_{(\mathrm{i})}$ with $\boldsymbol{t}_{\boldsymbol{k}(i)}=\boldsymbol{x}_{(i)} \cdot \boldsymbol{w}_{(\boldsymbol{k})}$ so that individual variables from $t$ of the data set comprise the maximum variation from $\mathrm{x}$ with each $\mathrm{w}$ vector, unit vector.

First vector $\mathrm{w}_{(1)}$ satisfies the relation:

$$
\mathrm{w}_{(1)}=\underset{\|\mathrm{w}\|=1}{\arg \max }\left\{\sum_{\mathrm{i}}\left(\mathrm{t}_{1}\right)_{(\mathrm{i})}^{2}\right\}={ }_{\|\mathrm{w}\|=1}^{\arg \max }\left\{\sum_{\mathrm{i}}\left(\mathrm{x}_{(\mathrm{i})} \cdot \mathrm{w}\right)^{2}\right\}
$$

Equivalent as matrix:

$$
\mathrm{w}_{(1)}=\underset{\|\mathrm{w}\|=1}{\arg \max }\left\{\|\mathrm{Xw}\|^{2}\right\}=\underset{\|\mathrm{w}\|=1}{\arg \max }\left\{\mathrm{w}^{\mathrm{T}} \mathrm{X}^{\mathrm{T}} \mathrm{Xw}\right\}
$$

And $\mathrm{w}_{(1)}$ is defined as unit vector; it results the relation:

$$
\mathrm{w}_{(1)}=\arg \max \left\{\frac{\mathrm{w}^{\mathrm{T}} \mathrm{X}^{\mathrm{T}} \mathrm{Xw}}{\mathrm{w}^{\mathrm{T}} \mathrm{w}}\right\}
$$

The $\mathrm{k}$ component is determined by the removal of the first $\mathrm{k}-1$ main components of $\mathrm{X}$ :

$$
\widehat{\mathrm{X}_{\mathrm{k}}}=\mathrm{X}-\sum_{\mathrm{s}=1}^{\mathrm{k}-1} \mathrm{Xw}_{(\mathrm{s})} \mathrm{w}_{(\mathrm{s})}^{\mathrm{T}}
$$

Then, it identifies the vector that removes the maximum variation from the new data matrix:

$$
\mathrm{w}_{(\mathrm{k})}=\underset{\|\mathrm{w}\|=1}{\arg \max }\left\{\left\|\widehat{\mathrm{X}_{\mathrm{k}}} \mathrm{w}\right\|^{2}\right\}=\arg \max \left\{\frac{\mathrm{w}^{\mathrm{T}} \widehat{\mathrm{X}}_{\mathrm{K}}^{\mathrm{T}} \widehat{\mathrm{k}_{\mathrm{k}}} \mathrm{w}}{\mathrm{w}^{\mathrm{T}} \mathrm{w}}\right\}
$$

$\mathrm{X}^{\mathrm{T}} \mathrm{X}$ is proportional with the covariance matrix of the $\mathrm{X}$ data set, and the covariance $\mathrm{Q}$ between the two main components is: 
A Factor Analysis of the Public Sector Performance. Significant Differences between Old and New EU Countries

$$
\begin{aligned}
\mathrm{Q}\left(\mathrm{PC}_{(\mathrm{j})}, \mathrm{PC}_{(\mathrm{k})}\right) \propto\left(\mathrm{Xw}_{(\mathrm{j})}\right)^{\mathrm{T}} \cdot\left(\mathrm{Xw}_{(\mathrm{k})}\right) \\
=\mathrm{w}_{(\mathrm{j})}^{\mathrm{T}} \mathrm{X}^{\mathrm{T}} \mathrm{Xw}_{(\mathrm{k})} \\
=\mathrm{w}_{(\mathrm{j})}^{\mathrm{T}} \lambda_{(\mathrm{k})} \mathrm{w}_{(\mathrm{k})} \\
=\lambda_{(\mathrm{k})} \mathrm{w}_{(\mathrm{j})}^{\mathrm{T}} \mathrm{w}_{\mathrm{k}}
\end{aligned}
$$

Eigenvectors $\mathrm{w}_{\mathrm{i}}$ and $\mathrm{w}_{\mathrm{k}}$ that correspond to the eigenvalues symmetric matrix are orthogonal.

The covariance matrix of the original variables can be thus written:

$$
\mathrm{Q} \propto \mathrm{X}^{\mathrm{T}} \mathrm{X}=\mathrm{W} \Lambda \mathrm{W}^{\mathrm{T}}
$$

The covariance matrix between the two main components becomes:

$$
\mathrm{W}^{\mathrm{T}} \mathrm{QW} \propto \mathrm{W}^{\mathrm{T}} \Lambda \mathrm{W}^{\mathrm{T}} \mathrm{W}=\Lambda
$$

Where $\Lambda$ is the eigenvalues orthogonal matrix $\lambda_{(\mathrm{k})}$ of

$$
\mathbf{X}^{\mathbf{T}} \mathbf{X} \text { și } \boldsymbol{\lambda}_{(k)}=\sum \mathbf{t}_{k(i)}^{2}=\sum\left(\mathbf{x}_{(\mathbf{i})} \cdot \mathbf{w}_{(k)}\right)^{2}
$$

As we already state, the model used by Afonso et al. (2006) is a reference for our empirical approach. By using the technique of composite indicators, the authors have considered the public sector efficiency as the performance of public sector in relationship to the relevant category of public expenditures; therefore, it is also possible to highlight the opportunity costs generated by achieving performance. However, this topic it was not considered for this paper.

We summed up our analysis to the performance composite index construction according to the mentioned reference. Multivariate statistical methods can be used to weight and aggregate variables in a composite index. An advantage of these methods is that they require no a priori assumptions about the weights of the different dimensions. From the multivariate statistical technique, principal component analysis (PCA) is useful for reducing and interpreting large multivariate data sets with underlying linear structures and for discovering previously unsuspected relationships and it was considered in this paper (Tabachnick and Finell 2012).

Data represent a strongly balanced panel for 28 European Union states, divided into "old" and "new" Member States and cover a time span between 1995 and 2014. The question addressed was to determine the EU membership status as "old" and "new", following the two enlargement waves in 2004 and 2007. Because we were concerned with identifying structural changes in public sector performance and not so much annual fluctuations, we employ observations for a period of at least 10 years. We find 2004 to be the year with the largest wave of enlargement in the history of the EU. Ten new countries, with a population of more than 100 million, 
Oana Lobont, Nicoleta Moldovan, Al. Bociu, Codruta Chis, Daniel Olariu

joined the European Union, including the following: Cyprus, Estonia, Latvia, Lithuania, Malta, Poland, the Czech Republic, Slovakia, Slovenia and Hungary.

In this paper, the EU membership status notes the following as "old" Member States: Austria, Belgium, Germany, Denmark, Spain, Finland, France, Greece, Ireland, Italy, Luxembourg, Netherlands, Portugal, Sweden and United Kingdom; this paper notes the following as "new" Member States: Bulgaria, Cyprus, Czech Republic, Estonia, Hungary, Lithuania, Latvia, Malta, Poland, Romania, Slovenia, Slovakia and Croatia.

Seven relevant sub-sector indicators for constructing public sector performance index were considered as follows: 1) Administration, measured through good governance indicators, namely, political stability and absence of violence, control of corruption, government effectiveness, regulatory quality and rule of law; 2) Education as early leavers from education and training, school enrolment lower secondary and quality of technology and science; 3) Health highlighted by life expectancy and infant mortality rate; 4) Infrastructure as electricity sources and water sources; 5) Distribution through the Gini index; 6) Stability measured through inflation and general government gross debt; and 7) Economic Performance captured by GDP growth rate, unemployment and GDP per capita rate. The data sources used in the computation of these indices consider the perceptions of various respondents such as citizens, companies, country analysis, international agencies and non-governmental organizations. The data also consider official information providers, of which we evaluate the Worldwide Governance Indicators for Administration dimension of public sector, Eurostat for Education, Health, Stability and Economic Performance dimensions of public sector and finally, the World Bank for the Distribution and Infrastructure domains.

\section{Results}

As we pointed out in the methodology section, factor analysis was applied for the considered variables as Public Sector governance sub-indicators. The descriptive analysis of the considered variables is presented below, with $\mathrm{N}=243$ (Table 1).

Table 1. Descriptive analysis of variables

\begin{tabular}{clll}
\hline $\begin{array}{c}\text { Main } \\
\text { variables }\end{array}$ & \multicolumn{1}{c}{$\begin{array}{c}\text { Public sector performance } \\
\text { sub-indicators }\end{array}$} & Mean & Std. Deviation \\
\hline \multirow{2}{*}{ Administration } & A1_Political Stability and Absence of Violence & 71.76 & 14.948 \\
& A2_Control of Corruption & 77.76 & 15.742 \\
& A3_Government Effectiveness & 80.69 & 14.031 \\
& A4_Regulatory Quality & 84.44 & 10.112 \\
& A5_Rule of Law & 79.57 & 14.98
\end{tabular}


A Factor Analysis of the Public Sector Performance. Significant Differences between Old and New EU Countries

\begin{tabular}{clll}
\hline $\begin{array}{c}\text { Main } \\
\text { variables }\end{array}$ & \multicolumn{1}{c}{$\begin{array}{c}\text { Public sector performance } \\
\text { sub-indicators }\end{array}$} & \multicolumn{1}{c}{ Mean } & Std. Deviation \\
\hline \multirow{2}{*}{ Education } & E1_Early leavers from education and training & 12.8148 & 6.81563 \\
& E2_School enrolment lower secondary & 29.4049 & 11.5159 \\
& E3_Quality of technology and science & 7.94 & 2.825 \\
Health & H1_Life expectancy & 76.9317 & 3.39332 \\
& H2_Infant mortality rate & 5.028 & 2.90398 \\
Infrastructure & I1_Electricity sources & 51.1408 & 28.23364 \\
& I2_Water sources & 98.7967 & 2.49925 \\
Distribution & D Gini index & 31.39 & 3.514 \\
Stability & S1_Inflation & 3.66 & 5.294 \\
& S2_General government gross debt & 51.0391 & 30.7427 \\
Economic & EP1_GDP growth & 2.1058 & 4.25355 \\
Performance & EP2_Unemployment & 8.8819 & 3.97917 \\
& EP3_Rate of GDP per capita & 1.9317 & 4.47151 \\
\hline
\end{tabular}

Source: Authors` processing

Within the table Communalities, the column Extraction shows the communality corresponding to each variable after drawing the factors (Table 2). Thus, the higher the communality of a variable, the more it tends to be suitable for the chosen model.

Table 2. Communalities

\begin{tabular}{|c|c|c|c|c|}
\hline \multirow{2}{*}{ Communalities } & \multicolumn{2}{|c|}{ Raw } & \multicolumn{2}{|c|}{ Rescaled } \\
\hline & Initial & Extraction & Initial & Extraction \\
\hline $\begin{array}{c}\text { Political Stability and Absence } \\
\text { of Violence }\end{array}$ & 223.453 & 120.846 & 1 & 0.541 \\
\hline Control of Corruption & 247.818 & 229.509 & 1 & 0.926 \\
\hline Government Effectiveness & 196.861 & 185.439 & 1 & 0.942 \\
\hline Regulatory Quality & 102.243 & 86.356 & 1 & 0.845 \\
\hline Rule of Law & 224.415 & 210.235 & 1 & 0.937 \\
\hline $\begin{array}{c}\text { Early leavers from education } \\
\text { and training } \\
\text { School enrolment lower }\end{array}$ & 46.453 & 7.429 & 1 & 0.16 \\
\hline & 132.616 & 43.999 & 1 & 0.332 \\
\hline science & 7.983 & 1.845 & 1 & 0.231 \\
\hline Life expectancy & 11.515 & 7.832 & 1 & 0.68 \\
\hline Infant mortality rate & 8.433 & 5.175 & 1 & 0.614 \\
\hline
\end{tabular}


Oana Lobont, Nicoleta Moldovan, Al. Bociu, Codruta Chis, Daniel Olariu

\begin{tabular}{|c|c|c|c|c|}
\hline \multirow{2}{*}{ Communalities } & \multicolumn{2}{|c|}{ Raw } & \multicolumn{2}{|c|}{ Rescaled } \\
\hline & Initial & Extraction & Initial & Extraction \\
\hline Electricity sources & 797.138 & 793.803 & 1 & 0.996 \\
\hline Water sources & 6.246 & 2.339 & 1 & 0.374 \\
\hline Gini index & 12.347 & 2.389 & 1 & 0.194 \\
\hline Inflation & 28.027 & 6.488 & 1 & 0.231 \\
\hline General government gross debt & 945.114 & 939.201 & 1 & 0.994 \\
\hline GDP growth & 18.093 & 2.905 & 1 & 0.161 \\
\hline Unemployment & 15.834 & 3.149 & 1 & 0.199 \\
\hline Rate of GDP per capita & 19.994 & 4.113 & 1 & 0.206 \\
\hline
\end{tabular}

Source: Authors`processing and Extraction Method: PCA

Likewise, own values were calculated, including percentages of explained version for each extracted factor and percentages of cumulative version, explained by all extracted factors before and after rotation (the used extraction method was Varimax, according to Figure 1).

\begin{tabular}{|c|c|c|c|c|c|c|}
\hline \multicolumn{7}{|c|}{ Total Variance Explained } \\
\hline \multirow[b]{2}{*}{ Component } & \multicolumn{3}{|c|}{ Initial Eigenvalues } & \multicolumn{3}{|c|}{ Rotation Sums of Squared Loadings } \\
\hline & Total & $\begin{array}{c}\% \text { of } \\
\text { Variance }\end{array}$ & $\begin{array}{c}\text { Cumulative } \\
\%\end{array}$ & Total & $\begin{array}{c}\% \text { of } \\
\text { Variance }\end{array}$ & $\begin{array}{c}\text { Cumulative } \\
\%\end{array}$ \\
\hline 1 & 6.568 & 36.486 & 36.486 & 6.155 & 34.195 & 34.195 \\
\hline 2 & 3.367 & 18.704 & 55.190 & 2.874 & 15.967 & 50.162 \\
\hline 3 & 1.794 & 9.966 & 65.156 & 2.442 & 13.565 & 63.727 \\
\hline 4 & 1.420 & 7.891 & 73.047 & 1.678 & 9.320 & 73.047 \\
\hline 5 & 0.995 & 5.528 & 78.574 & & & \\
\hline 6 & 0.941 & 5.226 & 83.800 & & & \\
\hline 7 & 0.720 & 4.002 & 87.802 & & & \\
\hline 8 & 0.604 & 3.355 & 91.157 & & & \\
\hline 9 & 0.419 & 2.329 & 93.486 & & & \\
\hline 10 & 0.317 & 1.761 & 95.247 & & & \\
\hline 11 & 0.260 & 1.447 & 96.694 & & & \\
\hline 12 & 0.241 & 1.338 & 98.033 & & & \\
\hline 13 & 0.124 & 0.690 & 98.723 & & & \\
\hline 14 & 0.095 & 0.529 & 99.251 & & & \\
\hline 15 & 0.056 & 0.309 & 99.560 & & & \\
\hline 16 & 0.044 & 0.246 & 99.807 & & & \\
\hline 17 & 0.028 & 0.155 & 99.962 & & & \\
\hline 18 & 0.007 & 0.038 & 100.000 & & & \\
\hline
\end{tabular}

Source: Authors' processing

Figure 1. Total Variance Explained

There were four eigenvalues greater than $1, \lambda 1=6.155, \lambda 2=2.874,3=2.442$ and $\lambda 4=1.678$; therefore, the model will contain 4 main components (Figure 1). Factor no. 1 explains $34.195 \%$ of the variance of variables, factor no. 2 explains $15.967 \%$, 
A Factor Analysis of the Public Sector Performance. Significant Differences between Old and New EU Countries

factor no. 3 explains $13.565 \%$ and factor no. 4 explains $9.32 \%$. The total variance explained by the four factors is $73.047 \%$, and some of these factors are representatives for the Administration domain. Administration domain refers to all public activities directed at policymaking, legislation and management of the public sector, as well as civil services directed towards the legal participation of citizens in society.

Figure 2 presents the Reproduced Correlations resulting from of the model's adequacy analysis by the four factors. The percentage of non redundant residue greater than 0.05 is $40 \%(<50 \%)$.

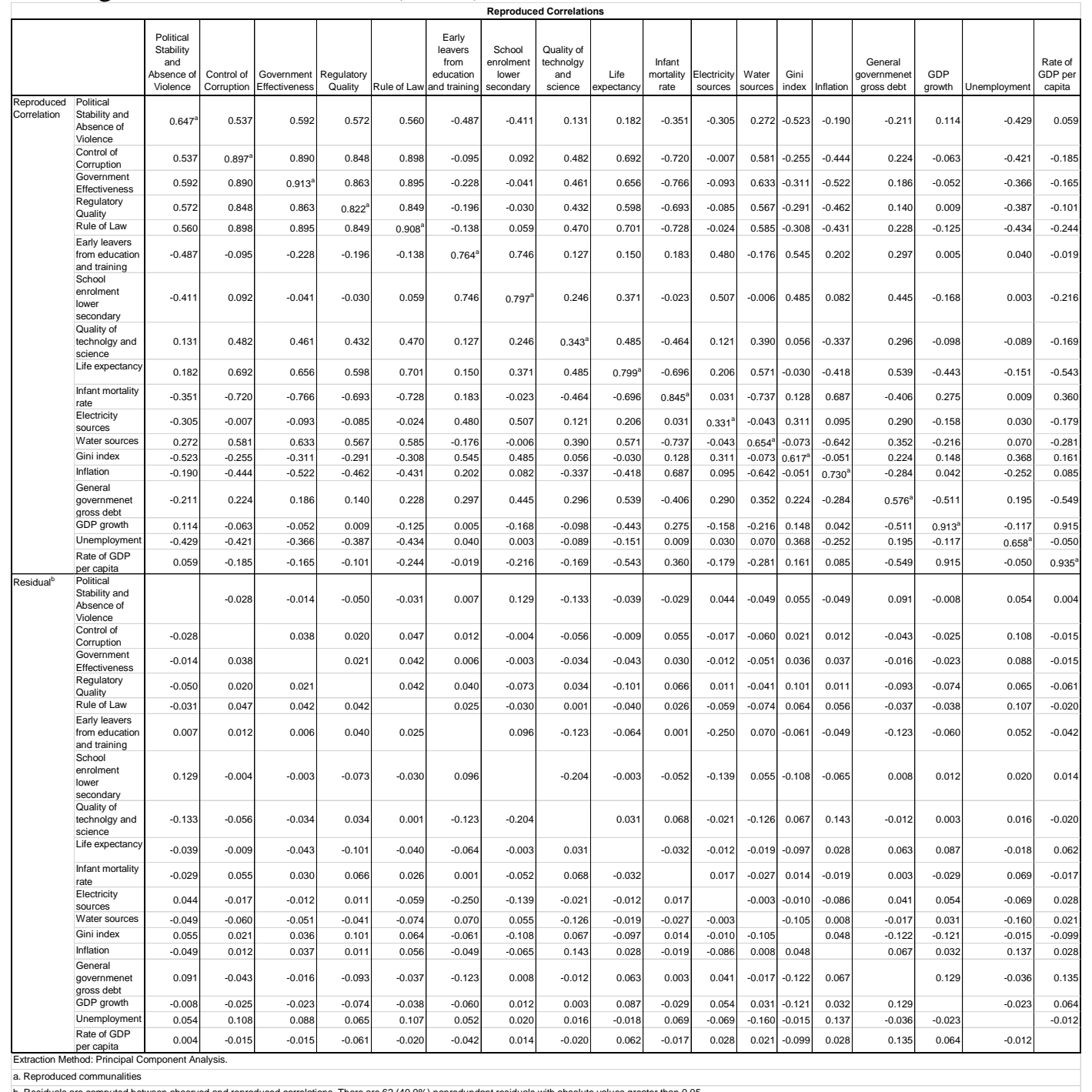

Source: Authors' processing

Figure 2. Reproduced Correlations 
Oana Lobont, Nicoleta Moldovan, Al. Bociu, Codruta Chis, Daniel Olariu

Grouping variables on the four factors are presented in Table 3. Rotated Component Matrix.

Table 3. Rotated Component Matrix

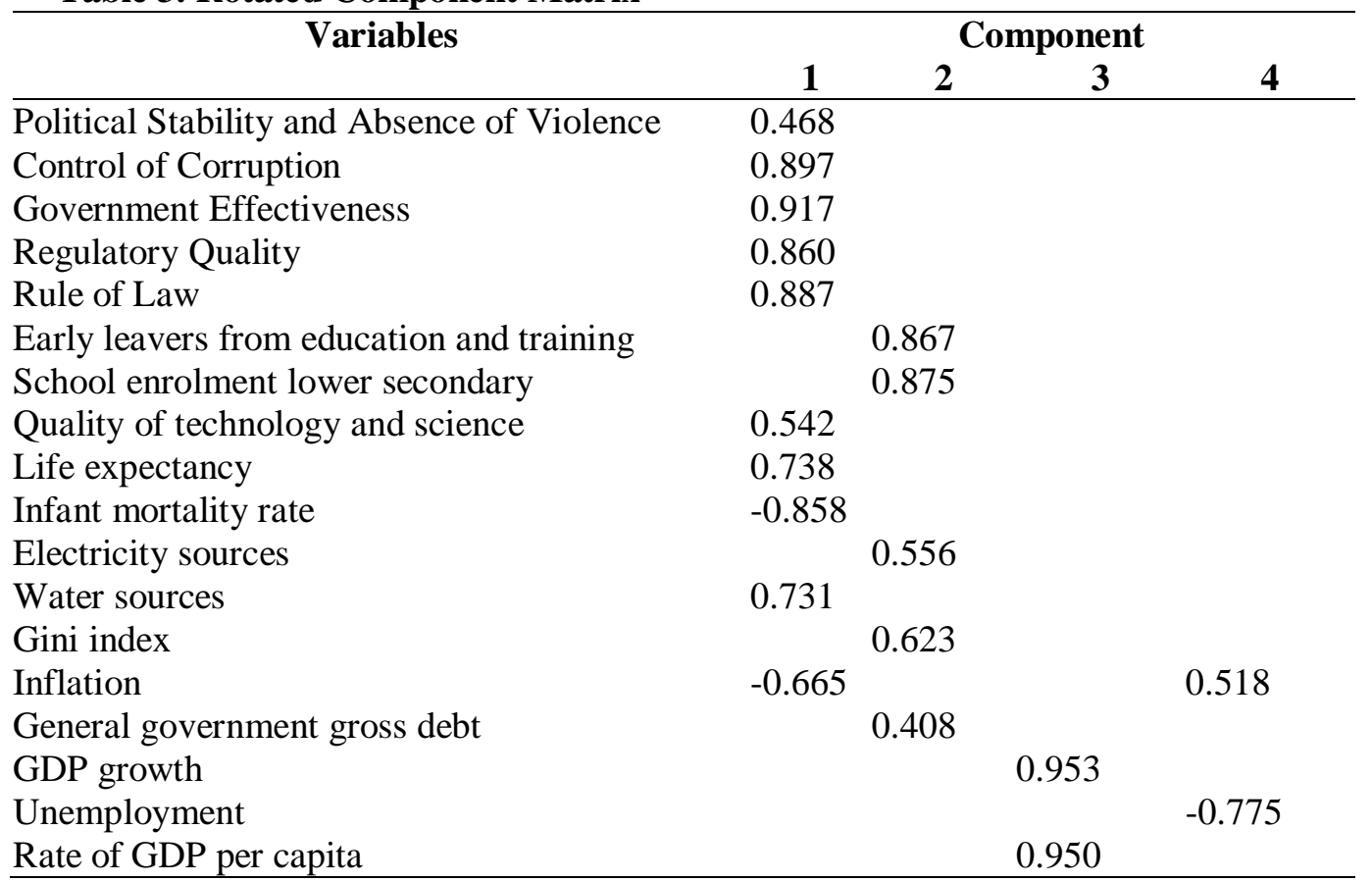

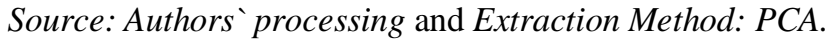

Rotation Method: Varimax with Kaiser Normalization - converged in 5 iterations.

In outlining the proposed model for the construction of a composite index of public sector performance, the factorial saturation with absolute values greater than 0.35 were held as follows:

- The first proposed factor (subindex) contains the following variables: Political Stability and Absence of Violence, Control of Corruption, Government Effectiveness, Regulatory Quality, Rule of Law, Quality of technology and science, Life Expectancy, Infant Mortality Rate, Water sources, Inflation.

- The second proposed factor (subindex) contains the following variables: Early leavers from education and training, School enrolment lower secondary, Electricity sources, Gini index, General government gross debt.

- Within the third factor, we find the following variables: GDP growth, and Rate of GDP per capita

- The fourth factor comprises: Inflation and Unemployment

Finally, the proposed model for public sector performance measurement is the computed Public Sector Performance Index. 
A Factor Analysis of the Public Sector Performance. Significant Differences between Old and New EU Countries

\section{Public Sector Performance Index}

$=(0.468 *$ Political Stability and Absence of Violence $+0.897 *$ Control of Corruption $+0.917 *$ Government Effectiveness $+0.860 *$ Regulatory Quality + $0.887 *$ Rule of Law $+0.524 *$ Quality of technology and science $+0.738 *$ Life expectancy + +0.858$) *$ Infant mortality rate $+0.731 *$ Water sources + $(-0.665) *$ Inflation)

$+\left(0.867 *\right.$ Early leavers from education and training $+0.875^{*}$ School enrolment lower secondary $+0.556 *$ Electricity sources $+0.623^{*}$ Gini index $+0.480 *$ General government gross debt)

$+(0.953 *$ GDP growth +0.95 Rate of GDP per capita $)$

$+(0.518 *$ Inflation $+(-0.775) *$ Unemployment $)$

By applying the obtained indicator for the performance analysis of EU countries and considering a two-way analysis of new and old countries in the EU, as well as an integrated analysis of all EU countries, we obtain the following results:

Table 4. Old and New EU countries' indicator values

\begin{tabular}{lcll}
\hline $\begin{array}{c}\text { Old countries' } \\
\text { indicator values }\end{array}$ & CI value & $\begin{array}{c}\text { New countries' } \\
\text { indicator values }\end{array}$ & CI value \\
\hline Austria & 505.08 & Bulgaria & 349.52 \\
Belgium & 499.42 & Croatia & 390.45 \\
Denmark & 506.64 & Cyprus & 467.36 \\
Finland & 517.44 & Czech Republic & 419.58 \\
France & 478.07 & Estonia & 438.55 \\
Germany & 502.62 & Hungary & 413.35 \\
Greece & 422.07 & Latvia & 407.93 \\
Ireland & 514.12 & Lithuania & 411.90 \\
Italy & 439.71 & Malta & 499.68 \\
Luxembourg & 489.19 & Poland & 414.64 \\
Netherlands & 517.67 & Romania & 369.40 \\
Portugal & 506.41 & Slovakia & 400.09 \\
Spain & 463.04 & Slovenia & 432.01 \\
Sweden & 499.82 & & \\
United Kingdom & 501.94 & & \\
\hline
\end{tabular}

Figure 3 reports the old and new EU member states classification groups based on the indicators considered in our analysis and the obtained country scores.

Clustering the old EU states indicates the existence of 3 groups of countries outlined on the basis of the considered sub-indicators and the composite indicator value the countries obtained. The first cluster comprises the countries with the highest level of performance due to the composite index scores (Denmark, Portugal, Austria, Belgium, Sweden, Germany, United Kingdom, Finland, Netherlands and 
Oana Lobont, Nicoleta Moldovan, Al. Bociu, Codruta Chis, Daniel Olariu

Ireland). We notice that the second cluster comprises the countries with an average performance according to the composite index score (France, Luxembourg and Spain). Finally, the third cluster comprises the countries with the lowest performance index score (Greece and Italy).

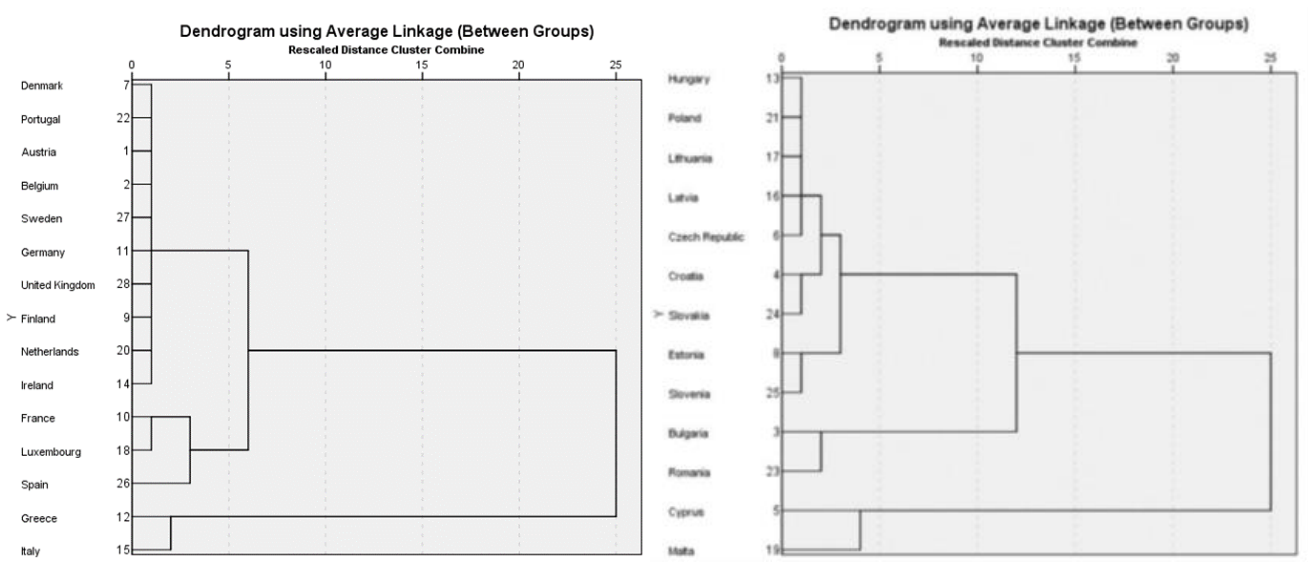

Figure 3. Dendogram of Old and New EU countries

Even in the case of new states within the EU, we identify the existence of 3 classification groups. The first cluster is composed of the countries with an average performance index score (Hungary, Poland, Lithuania, Latvia, Czech Republic, Croatia, Slovakia, Estonia and Slovenia). The second cluster comprises the countries with the lowest performance composite index score (Bulgaria and Romania). The third cluster comprises the countries with the highest performance according to composite index scores (Cyprus and Malta).

Table 5. Ranks

\begin{tabular}{ccccc}
\hline \multirow{3}{*}{ CI value } & Old/new country & $\mathbf{N}$ & Mean Rank & Sum of Ranks \\
& 0.00 & 15 & 20.27 & 304.00 \\
& 1.00 & 13 & 7.85 & 102.00 \\
\hline
\end{tabular}

Table 6. Mann-Whitney U

\begin{tabular}{|c|c|}
\hline \multicolumn{2}{|c|}{ Test Statistics $^{\mathrm{a}}$} \\
\hline & VAR00003 \\
\hline Mann-Whitney U & 11.000 \\
\hline Wilcoxon W & 102.000 \\
\hline & -3.985 \\
\hline Asymp. Sig. (2-tailed) & .000 \\
\hline
\end{tabular}


A Factor Analysis of the Public Sector Performance. Significant Differences between Old and New EU Countries

\begin{tabular}{l|l}
\hline Exact Sig. [2*(1-tailed Sig.)] & $.000^{\mathrm{b}}$
\end{tabular}

a. Grouping Variable: VAR00005

b. Not corrected for ties.

Taking an integrated approach to the results of all EU countries, we apply the Mann-Whitney U test (Table 5, Table 6) and deduce that there are significant differences $(U=11.00, p=0.000)$ between $E U$ countries in terms of the aggregate index, with the scores of the old countries being higher than the scores of new countries. Analyzing the clustering of all EU member states, we identify three clusters, of which there is an almost total difference between old and new EU countries, except for four states, namely, Greece, Italy, Malta and Cyprus (Figure 4).

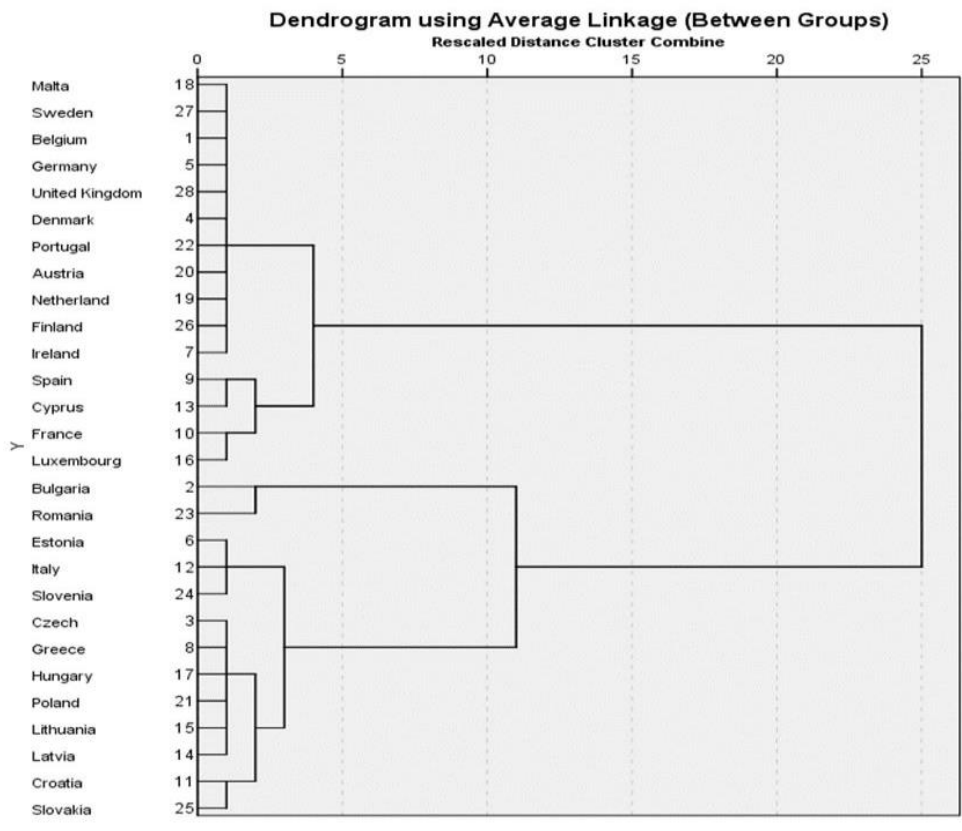

Figure 4. Dendogram of all EU countries

The first cluster is composed of the most performant states, as a result of the composite index score and consists of all the old EU countries, except Italy and Greece and additionally contains two new EU countries, Malta and Cyprus. The second cluster contains two new EU member countries with the lowest performance results, Bulgaria and Romania. The last cluster comprises the new EU states and additionally contains two old states in the EU, Italy and Greece; the results of the states in this cluster are averages.

Our results are consistent with others several studies, which have shown that the public performance of countries is powerful in relationship to the presence of independent institutions, independent judiciary, consumer protection agencies, an 
independent central bank, and independent regulation. A close analysis of the World Bank Indicators reveals that the Western and Northern European countries have the best administration indicators scores. These countries also represent the old EU countries, the countries with the best composite index scores in our study.

Results on countries performance using the Public Sector Performance Index could be a consequence of the national policy adopted by each country. The European Commission identifies three essential components needed to achieve a performant national policy to gain development. The components are as follows: (i) Policy design; (ii) Forward planning and (iii) Consultation and co-responsibility. Policy design refers to a solid evidence base and a good interpretation. Policymakers should seek a wide net when choosing sources by including national and international official statistics, academia, studies, etc. Forward planning refers to the fact that governments should engage in longer-term strategic planning for up to ten to twenty years. Consultation and co-responsibility refers to the role that citizens and other interested parties play in national policy agenda. Public consultation plays a major role in this context.

New EU countries have to learn from the executive probity and the performant public policies of the older countries in the EU. The functional structure of the European Union encourages constructive coexistence between countries as well as the process of learning from the experiences of others.

\section{Conclusion}

In this study, we empirically assess the EU countries public sector aggregated performance. It can be notice that the analysis of public sector performance is a challenging and complex action. It was necessary to consider several basic dimensions within a state, when undertaking a comprehensive and exhaustive analysis in this respect. Developing a robust comparability framework between states is a necessity and already was initiated and sustained both by the academic community and certain international institutions. The need to build this framework also lies in the need for states to shape a performance-benchmarking barometer for comparison with other countries in the world. In this paper, we identified several international institutions that perform comparisons between countries using composite indicators, obtained by aggregating different sectors of public environment that are considered relevant for a dynamic and judicious analysis of sustainable public sector performance. The starting point of our research was based on the approach used by Afonso et al. (2003, 2006, 2013) [2-4], which compiles performance and efficiency composite indicators by aggregating seven sub-indicators, as the most exciting and edifying in the performance analysis of the public sector of all its economic, social and political dimensions. The analysis of public sector performance outweighs the efficiency analysis framework achieved through non-parametric methods of reporting the efficiency production frontier and involves the development of a more complex analysis. We identified principal 
A Factor Analysis of the Public Sector Performance. Significant Differences between Old and New EU Countries

component analysis as an effective tool to construct composite indicators, using the orthogonal linear transformation that transposes data into a coordinate system.

The results indicate that the composite indicator achieved by the aggregation of Administration, Education, Health, Infrastructure, Distribution, Stability and Economic Performance consists of four main components, of which the Administration plays the most powerful and responsible role. Using PCA, we determined a composite index able to determine the performance of the public sector. Our results also reveal a strong distinction of indicator values for the European Union's "old" and "new" countries. This fact was also confirmed by the application of the Mann-Whitney $U$ test. Hence, the results indicate that EU old countries have the best competitive potential for prospective and perspective for further development.

Empirical performed analysis illustrated a clear distinction of indicator values for old and new EU countries. Only four states made a discordant note of this phenomenon, two old EU countries being considered with average performance results and two new EU states being considered with high-performance results, by using the composite index. Considering the most representative domains within a state, with importance and high level of impact on public policy outcomes and spending efficiency, it can be noted that public administration modernization and transformation is the primary factor responsible for development. Its dimensions should be considered, in a comprehensive manner, namely, Political Stability and Absence of Violence, Control of Corruption, Government Effectiveness, Regulatory Quality and Rule of Law, as a conclusive and robust tool for the decision-making process.

This paper supports and encourages the development of tools and frameworks to compare the performance of the public sector toward universal measurement methods that are applicable to all countries. Our research contributes to these approaches through the composite index and the results obtained by using it. In long-term planning for sustainable development, but not economic performance, a proper public administration system is the most important area to be looked upon, as a stand-alone development objective.

\section{REFERENCES}

[1] Afonso, A., Schuknecht., L., Tanzi,V. (2003), Public Sector Efficiency: An International Comparison. Working Paper Series, 242;

[2] Afonso, A., Schuknecht., L., Tanzi,V. (2006), Public Sector Efficiency: Evidence for New EU Member States and Emerging Market. Working Paper Series, 581;

[3] Afonso, A., Romero, A.,Monsalve E. (2013), Public Sector Efficiency: Evidence for Latin America. Inter-American Development Bank, Fiscal and Municipal Management Division, Discussion Paper, IDB-DP-279;

[4] Afonso, A., Schuknecht, L.,Tanzi, V.(2005), Public Sector Efficiency: An International Comparison. Public Choice, 123 (3-4), 321-347; 
Oana Lobont, Nicoleta Moldovan, Al. Bociu, Codruta Chis, Daniel Olariu

[5] Aigner, D.J., Lovell, C.A.K., Schmidt, P.(1977), Formulation and Estimation of Stochastic Frontier Production Functions. Journal of Econometrics, 6,21-37;

[6] Angelopoulos K., Philippopoulos A., Tsionas E. (2008), Does Public Sector Efficiency Matter? Revisiting the Relation between Fiscal Size and Economic Growth in a World Sample. Public Choice, 137, 245-278;

[7] Banker, R.D., Charnes, A., Cooper, W.W. (1984), Some Models for Estimating Technical and Scale Inefficiencies in Data Envelopment Analysis. Management Science, 30,1078-1092;

[8]Charnes, A., Cooper, W.W., Rhodes, E. (1978), Measuring the Efficiency of Decision Making Units. European Journal of Operational Research 2, 429-444;

[9] Deprins, D., L. Slmar, H., Tulkens (1984), Measuring Labor-Efficiency in Post Offices. The Performance of Public Enterprises: Concepts and Measurement; Elsevier, 1984, 243-267;

[10]Europe 2020 strategy. Available online: https://ec.europa.eu/info/strategy/european-semester/framework/europe-2020-strat egy_en

[11] Farrell M.J.(1957), The Measurement of Productive Efficiency. J.R. Statis. Soc. A 120, 253-281;

[12] Kaufmann A., Kraay A., Zoido-Lobaton P.(1999a), Aggregating Governance Indicators. Policy Research Working Paper;

[13] Kaufmann A., Kraay A.,Aart and Mastruzzi (2010), The Worldwide Governance Indicators: Methodology and Analytical Issues. World Bank Policy Research Working Paper, 5430;

[14] Lambsdorff J.G. (2005), Consequences and Causes of Corruption - What do we Know from a Cross-section of Countries?. Diskussionsbeitrag, V-34-05;

[15] OECD Annual Report 2007;

[16] Rouag A., Stejskal J.(2014), Measurement of the Public Sector Efficiency and Performance in Mena Region via Composite Index Approach. 5th Central European Conference in Regional Science - CERS 2014;

[17] Tabachnick, B., Fidell, L. (2012), Using Multivariate Statistics, Hardcover. Pearson Publisher;

[18] Tampieri L. (2005), Performance Evaluation Indexes in Public AdministrationSome Issues of their Actual Usefulness. Uprava, III;

[19] The World Bank's Country Policy and Institutional Assessment, Available online:http://databank.worldbank.org/data/reports.aspx?source=country-pol icy-and-institutional-assessment;

[20] World Economic Forum, Available online: https://www.weforum.org. 